ZOOLOGIA 32 (6): 445-456, December 2015

http://dx.doi.org/10.1590/S1984-46702015000600003

\title{
More on the Mesopotamian-Yungas disjunction in subtropical and temperate Argentina: Bioclimatic distribution models of the harvestman Discocyrtus dilatatus (Opiliones: Gonyleptidae)
}

\author{
Julia Vergara ${ }^{1} \&$ Luis E. Acosta ${ }^{1, *}$ \\ 'Instituto de Diversidad y Ecología Animal (IDEA), CONICET - Universidad Nacional de Córdoba, and Cátedra de Diversidad \\ Animal I, Facultad de Ciencias Exactas, Físicas y Naturales, U.N.C., Av. Vélez Sarsfield 299, X5000JJC Córdoba, Argentina. \\ "Corresponding author. E-mail: luis.acosta@unc.edu.ar
}

\begin{abstract}
In this paper, the potential distribution of the Mesopotamian harvestman Discocyrtus dilatatus Sørensen, 1884 is modeled, and the species' bioclimatic profile is described. Models were built with the presence-only methods MAXENT and BIOCLIM, using 85 unique records (of which 49 are new) and 11 non-correlated bioclimatic variables as predictors. Both MAXENT and BIOCLIM supported the Mesopotamian-Yungas disjunct pattern observed in D. dilatatus, and confirmed the hypothesis that the sub-xeric Dry Chaco is an effective barrier for the two portions of the range. Similarly to results of previous studies on other Mesopotamian harvestmen, temperature variables proved more relevant than precipitation variables in the final models. In the combined overall score obtained with MAXENT, bc4-temperature seasonality ranked as the most relevant, and only one precipitation variable (bc18-precipitation of warmest quarter, in second place) ranked among the top five. In the Most Limiting Factor analysis, which identifies the relevant variables in a local scale, temperature variables were again more determining than precipitation variables in most of the range. One single variable, bc5-maximal temperature of warmest month, proved critical near the boundaries of the modeled range and the Dry Chaco, suggesting that extremely high temperatures (and not the supposed aridity) are responsible for the $450 \mathrm{~km}$ distribution gap.
\end{abstract}

KEY WORDS. BIOCLIM; bioclimatic profile; MAXENT; most limiting factor; species distribution models.

While knowledge of the geographical distribution of a species starts with its actual records, correlative modeling methods help to identify the role of environmental variables in the shape of ranges, and to predict potential presences where samplings are still incomplete (RAXworthy et al. 2003, Elith \& Leathwick 2009, Pearson 2010). In recent years, several contributions have gradually improved our understanding of the distribution patterns of the harvestmen inhabiting the "Mesopotamian sensu stricto" opiliogeographical area, as defined by Acosta (2002). The harvestmen assemblages of this area comprise not only the Argentinean Mesopotamia (i.e., the region enclosed by the Uruguay and Paraná rivers), but also adjacent regions in eastern Paraguay, the provinces of Formosa, Chaco and Santa $\mathrm{Fe}$, along with a large westward projection into the plains of the province of Córdoba (Acosta 2002, see also Fig. 1). Our increased knowledge about species distributions results not only from gathering "more dots on a map", but also from the implementation of Species Distribution Models (SDM), using bioclimatic variables as predictors, on several typical Mesopotamian harvestmen: Discocyrtus prospicuus (Holmberg, 1876), Gryne orensis (Sørensen, 1879) and Discocyrtus testudineus (Holmberg, 1876) (Acosta \& GuerRero
2011, Acosta \& Vergara 2013, Acosta 2014). Aside from providing predictive models for these species, SDMs (frequently referred to as "ecological niche models") have allowed us to learn more about their bioclimatic requirements and tolerance ranges, which were mostly unknown for Neotropical harvestmen (Acosta 2008, 2014, Acosta \& Guerrero 2011). When based on climatic constraints, SDMs allow the "bioclimatic profile" of a given species to be inferred, i.e., the suite of optimal climatic conditions in which the populations of a species can be maintained. A projection on the map of this partial representation of the "bioclimatic niche" displays all areas deemed suitable for the species, under the parameters used, even if effective records do not cover the entire area (GUISAN \& Zimmermann 2000, PeARson 2010).

As stressed elsewhere, Discocyrtus dilatatus Sørensen, 1884 is probably the harvestman species that best defines the Mesopotamian s.s. distribution pattern (Acosta 2002, Fig. 1). Its distribution is rather continuous over an extensive area, from eastern Paraguay to the south of the provinces of Santa Fe and Entre Ríos, also entering the plains of the province of Córdoba (where it becomes one of the most frequent harvestmen), reaching the base of the central Sierras (Acosta 1995,

2015 | Sociedade Brasileira de Zoologia | www.sbzoologia.org.br | www.scielo.br/zool All content of the journal, except where identified, is licensed under a Creative Commons attribution-type BY. 


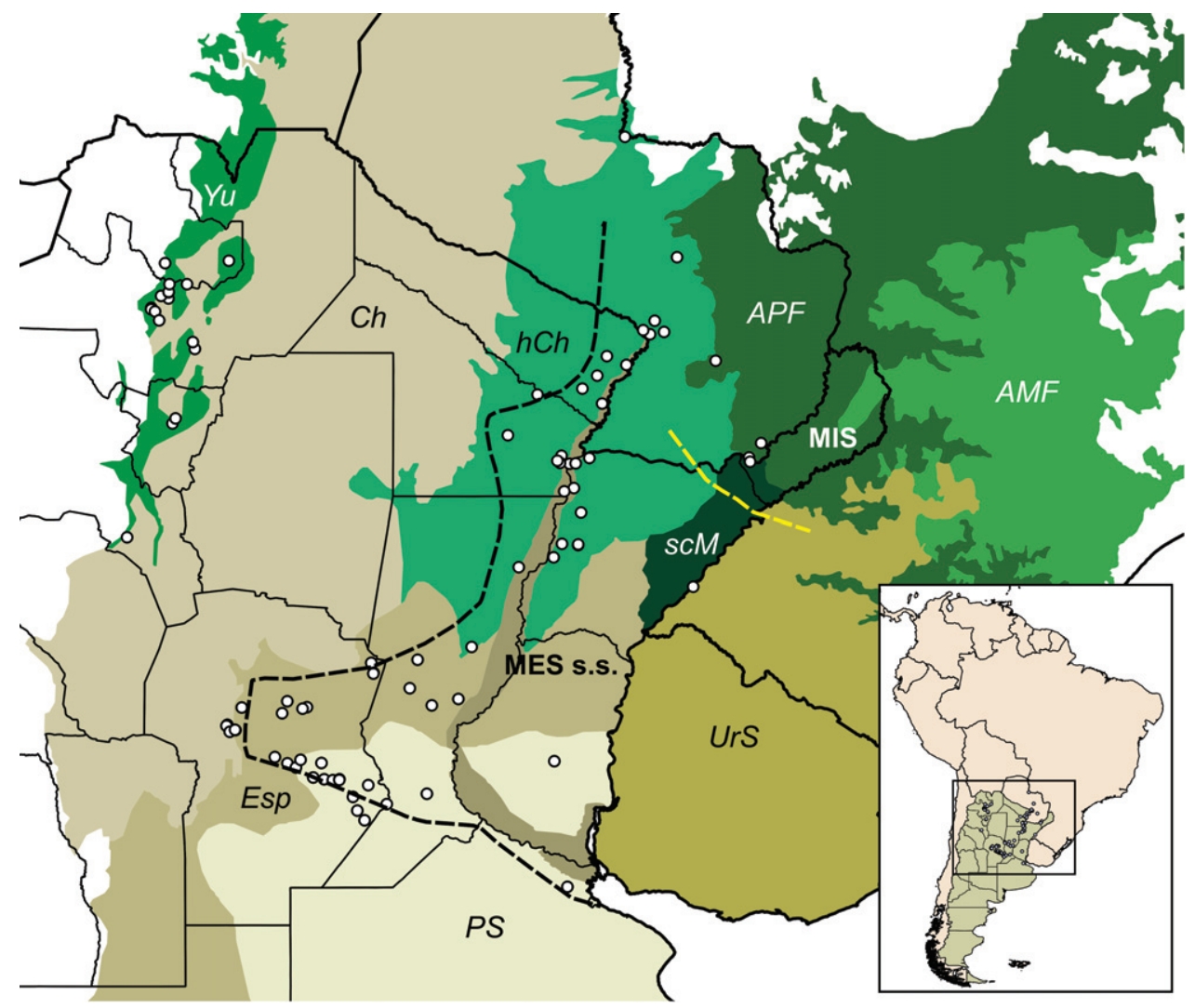

Figure 1. Records of Discocyrtus dilatatus (dots), plotted over the relevant ecoregions, as defined by Olson et al. (2001): Yungas (Yu), Dry Chaco (Ch), Humid Chaco (hCh), Espinal scrubland (Esp), Humid Pampean steppe (PS), Uruguayan savanna (UrS), Southern Cone Mesopotamian savanna (scM), Alto Paraná Atlantic Forests (APF), Araucaria moist forests (AMF); the narrow area along the Parana river course represents the Paraná flooded savanna. "Mesopotamian sensu stricto" (MES s.s.) and the Misiones (MIS) opiliogeographical areas in Argentina are indicated (based on Acosta 2002); black dashed line: west limit of MES s.s.; yellow dashed line: limit between MES s.s. and MIS. Inset: location of the depicted area in South America.

2002). The range of $D$. dilatatus is thus environmentally heterogeneous, stretching over several ecoregions (Fig. 1). In the Mesopotamia (the core area), D. dilatatus is widely sympatric with G. orensis and D. testudineus (Acosta \& Vergara 2013, Acosta 2014). One remarkable feature of the range of $D$. dilatatus is its occurrence in the montane rainforests of northwestern Argentina (Yungas ecoregion sensu Olson et al. 2001), about $450 \mathrm{~km}$ away from the species' core area (Acosta 1995, 2002, Fig. 1). The gap in-between corresponds to the Dry Chaco ecoregion, an extensive semi-arid environment that is deemed inhospitable for harvestmen from humid and sub-humid areas (AсоsTA 2002); thus, low precipitation appears at a first glance to be an explanation for the discontinuity. The disjunct pattern has been also documented for other Mesopotamian species (G. orensis, also in D. prospicuus, "marginal" in the area), as well as for a representative of the adjacent Misiones opiliogeographical area (Fig. 1: MIS), Geraeocormobius sylvarum Holmberg, 1887 (AcosTA 2002, 2008, Acosta \& Guerrero 2011, Acosta \& Vergara 2013).
Since several species are involved in what seems to be a more general pattern of distribution, an explanation invoking Pleistocene climatic cycles has been suggested: humid-warm periods (interglacials) may have enabled range expansions that connected both parts of the present range; subsequent cooldry stages (glacial) might have caused range retraction and isolation of the Yungas populations (Acosta 1995, 2002, ACOSTA \& Guerrero 2011, Acosta \& Vergara 2013; in accordance to the "forest bridges" proposed by Nores 1992 for birds). This hypothesis, however, remains to be tested.

Among the most characteristic Mesopotamian species, D. dilatatus is the only one for which a SDM has not been generated. For this reason, the primary goal of this paper is to model the distribution of $D$. dilatatus using bioclimatic predictors, and to assess which variables may influence the shape of the species' range more strongly. Particularly we wanted to identify the climatic drivers responsible for the range gap (Mesopotamia-Yungas disjunction) mentioned above. As 
stressed, aridity of the Dry Chaco seems to be an intuitively straightforward explanation. However, in the case of other disjunct species (D. prospicuus and G. orensis), temperature variables proved to be decidedly more relevant than precipitation variables, while a single variable ("maximal temperature of warmest month") has been considered a limiting factor close to the boundaries of the Chaco (Acosta \& Guerrero 2011, Acosta $\&$ Vergara 2013). We were particularly interested to find out if these conclusions also apply to $D$. dilatatus. Descriptive statements about the species' bioclimatic profile, together with analysis of the relevance of variables and the introduction of many new presence records give a complete update on the distributional features of $D$. dilatatus.

\section{MATERIAL AND METHODS}

\section{Presence data}

All available records of $D$. dilatatus were considered in the dataset used for modeling. Localities referred to in the literature (Sørensen 1884, 1895, Roewer 1913, 1929, 1938, Müller 1918, Ringuelet 1959, Soares \& Soares 1985, Acosta 1995, 2002) were all carefully evaluated, discarding the records that could not be identified or that were too imprecise to be georeferenced. New records were obtained from fieldwork and specimens gathered from different collections, resulting in a substantial increase of the record set. Localities obtained from the literature and specimens' labels were identified and georeferenced with use of road maps and digital gazetteers available on the Internet, chiefly Google Earth $^{\odot}$; our own captures were georeferenced in situ, using a Map-60 Garmin GPS. Collection acronyms are as follows: CDA: Cátedra de Diversidad Animal I, Facultad de Ciencias Exactas, Físicas y Naturales, Universidad Nacional de Córdoba (conventional collection is indicated with a 000.xxx accession number; freezer collection is denoted as CDA-F); LEA: Luis E. Acosta collection, Córdoba; MACN: Museo Argentino de Ciencias Naturales "Bernardino Rivadavia", Buenos Aires; IML: Instituto Miguel Lillo, San Miguel de Tucumán.

\section{Climatic variables}

Models were built using the climatic information contained in WorldClim 1.4 (Hujmans et al. 2005a). This database comprises a set of values for current climate, averaging the 19502000 period, in the form of 19 bioclimatic (bc) variables, referring both to temperature and precipitation (Table 1). Climate surfaces were delimited between $-73.541667^{\circ} \mathrm{W} /-47.966667^{\circ} \mathrm{W}$, and $-19.125000^{\circ} \mathrm{S} /-41.30000^{\circ} \mathrm{S}$, at the finest resolution available (30 arc second). To avoid overparametrization in the modeling procedure, we discarded highly correlated variables

Table 1. Bioclimatic profile of Discocyrtus dilatatus $(n=85)$ (BıсLı): basic statistics of the 19 bioclimatic variables and description of the cumulative frequency curves (cum. f.). Curves are characterized as normal (N), skewed towards the lower (sk-) or upper end (sk+), bimodal (Bi) with high peak at the right $\left(\mathrm{Bi}^{\wedge}\right)$ or at the left $\left({ }^{\wedge} \mathrm{Bi}\right)$ and multimodal $(\mathrm{M})$; the number of extreme low (left) and high (right) outliers in the curves are provided. Temperature values are in Celsius degrees $\left({ }^{\circ} \mathrm{C}\right)$, precipitation in millimeters. The 11 variables employed in the MAXENT models are asterisked.

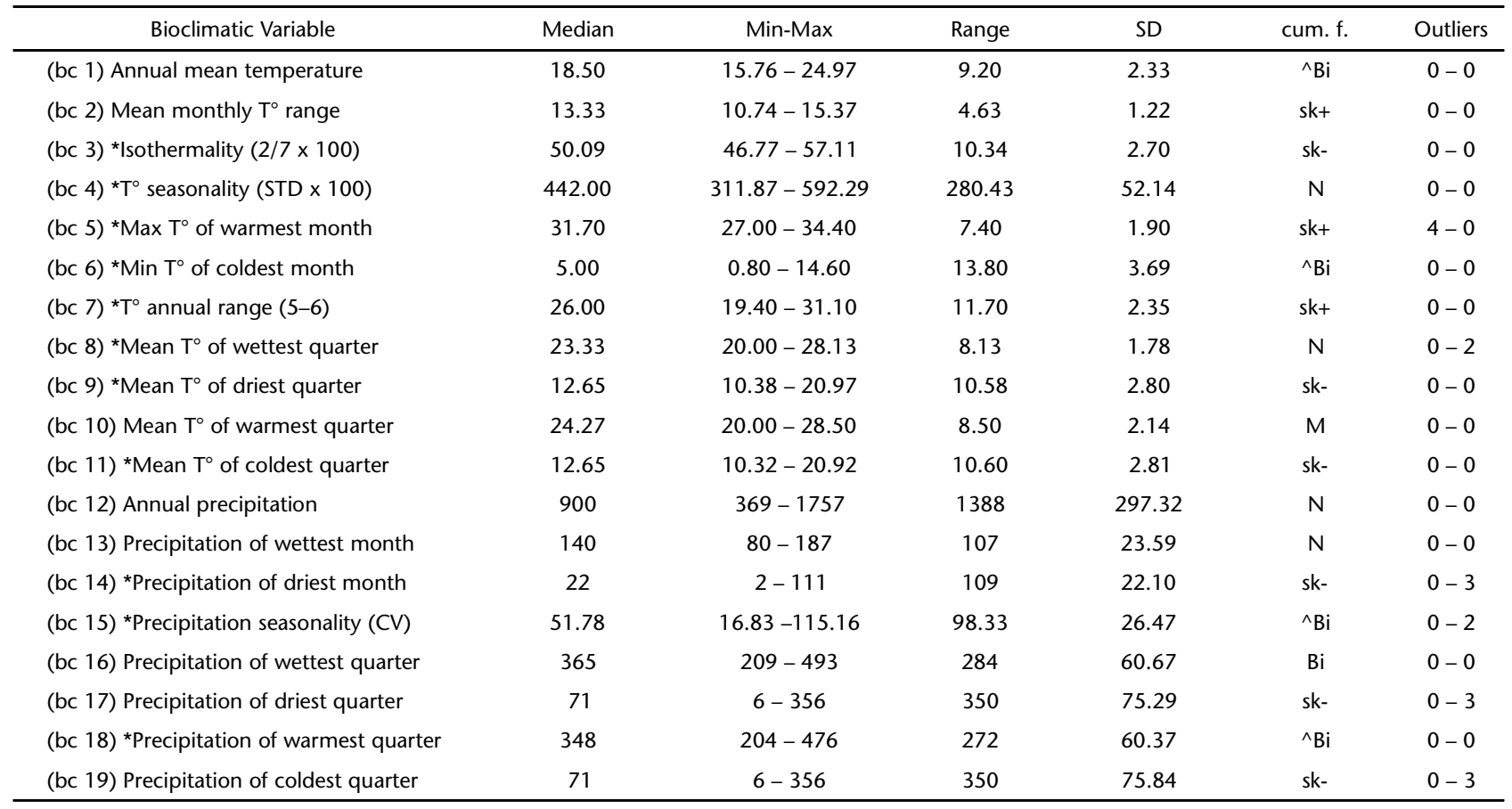


(Pearson $>0.75$ ) by conducting pairwise analyses separately for temperature and precipitation variables (RIsSLer \& APODACA 2007, KozaK et al. 2008, Acosta \& Guerrero 2011). The correlation was calculated on the bc values of 770 random points over the studied region (covering central and northern Argentina, Paraguay, Uruguay and southern Brazil). In view of the lack of prior biological information on the environmental preferences of $D$. dilatatus, the choice of a variable in a highly correlated pair was based on its relative contribution in preliminary MAXENT models (see below), carried out with all 19 variables; by doing this, our aim was to avoid the exclusion of potentially relevant predictors. Eleven uncorrelated bc variables were then used to build the models (Table 2).

\section{Calibration and evaluation of models}

The potential range of $D$. dilatatus was modeled with two presence-only, correlative algorithms, MAXENT and Bioclim. MAXENT models were built using version 3.3.3.k of the software (Phillips et al. 2011). As defined by Phillips et al. (2006), this method allows the estimation of a target probability distribution by finding the probability distribution of maximum entropy (i.e., that is most spread out, or closest to uniform), subject to a set of constraints that represent our incomplete information about the target distribution. Since suitability in MAXENT prediction maps is expressed in a continuous range (from 0 to 1 in the logistic output, here used), a threshold rule was used to define a limit between suitable and not suitable cells. In this study, the "maximum training sensitivity plus specificity" threshold was applied (Liu et al. 2005, Rubio \& Acosta 2011). Most settings were left in their default (recommended) values, but maximal number of background points was set to 25000, and maximum iterations to 3500. The MAXENT model of Fig. 3 displays suitability levels based on a single run. That of Fig. 2 is a binary prediction, i.e., "present/absent". Following AcosTA
(2014), binary maps summarize 30 replicate runs, using the "crossvalidation" option of replicate type; "random seed" was selected, and $10 \%$ of the points were used to test in each run. The final binary prediction was obtained by overlapping the 30 single binary maps, retaining as suitable those cells shared by $60 \%$ of the individual runs (Fig. 2). Bıоclim models were primarily built to contrast the results obtained in MAXENT. This method was run in the software Diva-Gis (Hijmans et al. 2005b). In this paper, only the binary ("true/false") BiocLim prediction was considered, with a cutoff at the 1.25 percentile (Fig. 2). Accuracy of the models obtained in Maxent and Bioclim was evaluated through the AUC (area under the curve) value, calculated in a ROC (receiver-operating characteristic) graph. AUC values over 0.8 are deemed to reflect a "good" model performance; above 0.9 the accuracy is considered "high" (Luoto et al. 2005).

\section{Bioclimatic profile}

To describe the bioclimatic conditions that are favorable to $D$. dilatatus, the set of values for all 19 bioclimatic variables were extracted using the Modeling > Bioclim > Envelope $>$ Extract command of Diva-Gis. Environmental preferences of the species were then characterized through the maximum, minimum, average and range values for each variable (Table 1). Distribution frequency features of the variables were tackled through the inspection of the cumulative frequency curves (classified following Acosta 2014); box-plot diagrams (obtained with the InfoStat package; Di Rienzo et al. 2013) were used to assess distribution outliers.

\section{Relevance of variables}

Different estimators, available in MAXENT, were used to measure the overall relevance of each variable in the predictive models of $D$. dilatatus. The "percent contribution" and the "permutation importance" were calculated by default by

Table 2. Relative importance of the 11 bc variables used to build the MAXENT model of $D$. dilatatus. Estimators include: (a) percent contribution of each variable to the model; (b) permutation importance; (c) jackknife analysis, training gain with each variable set aside at a time; and (d) jackknife, training gain with each variable run in isolation. Variables are ordered according to an overall scoring (last column), computing all four estimators $(a+b-c+d)$. In each column, the five highest values are in bold and the highest one is underlined.

\begin{tabular}{|c|c|c|c|c|c|}
\hline Variable & $\begin{array}{l}\text { (a) Percent } \\
\text { contribution }\end{array}$ & $\begin{array}{l}\text { (b) Permutation } \\
\text { importance }\end{array}$ & $\begin{array}{l}\text { (c) Training gain } \\
\text { without }\end{array}$ & $\begin{array}{l}\text { (d) Training gain } \\
\text { with only }\end{array}$ & $\begin{array}{l}\text { Overall } \\
\text { score }\end{array}$ \\
\hline bc4 $-\mathrm{T}^{\circ}$ seasonality & 15.8468 & $\underline{33.3324}$ & 2.0054 & 0.6669 & 47.8407 \\
\hline bc18 - Precipitation of warmest quarter & 22.4484 & 7.9319 & 1.9799 & 0.6949 & 29.0953 \\
\hline bc11 - Mean $\mathrm{T}^{\circ}$ of coldest quarter & 10.0974 & 18.7511 & 2.0435 & 0.7335 & 27.5385 \\
\hline bc9 - Mean $\mathrm{T}^{\circ}$ of driest quarter & 6.2910 & 18.7582 & 2.0198 & $\underline{0.7572}$ & 23.7866 \\
\hline bc $6-$ Min $\mathrm{T}^{\circ}$ of coldest month & 7.4027 & 10.7705 & 1.9852 & 0.3217 & 16.5097 \\
\hline bc15 - Precipitation seasonality & 9.8947 & 2.4110 & 2.0130 & 0.2226 & 10.5153 \\
\hline $\mathrm{bc} 8-$ Mean $\mathrm{T}^{\circ}$ of wettest quarter & 7.9686 & 2.0939 & 2.0300 & 0.5085 & 8.5410 \\
\hline $\mathrm{bc} 7-\mathrm{T}^{\circ}$ annual range & 6.5079 & 2.8311 & 2.0249 & 0.5594 & 7.8735 \\
\hline bc3 - Isothermality & 7.5586 & 1.5685 & 2.0184 & 0.5289 & 7.6376 \\
\hline bc5 - Max $\mathrm{T}^{\circ}$ of warmest month & 5.5620 & 1.3066 & 2.0403 & 0.2861 & 5.1144 \\
\hline bc14 - Precipitation of driest month & 0.4220 & 0.2448 & 2.0522 & 0.2103 & -1.1751 \\
\hline
\end{tabular}

ZOOLOGIA 32 (6): 445-456, December 2015 


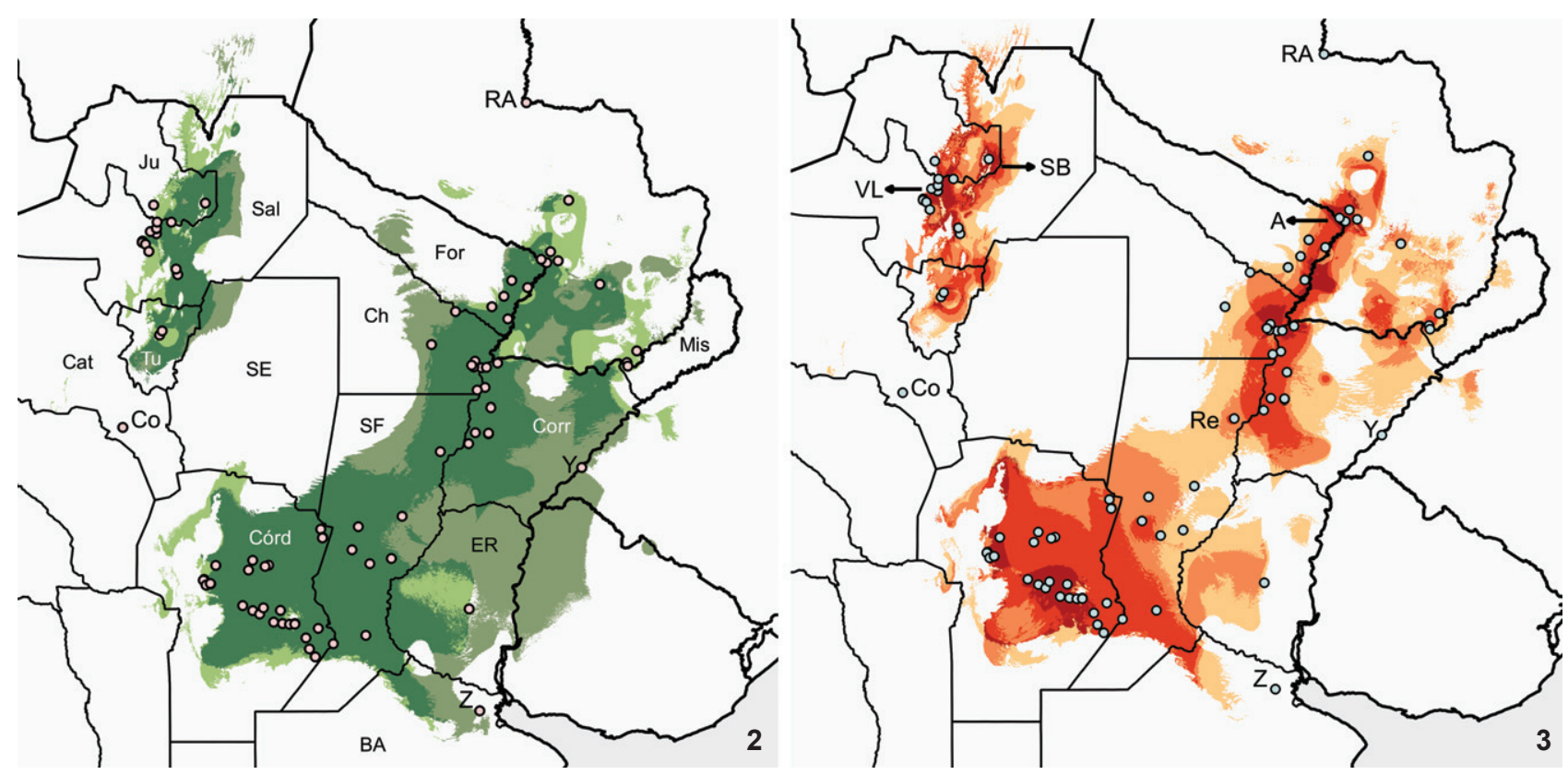

Figures 2-3. Distribution models of Discocyrtus dilatatus, calibrated with the 11 bc selected variables. (2) Overlap of binary models obtained with MAXENT and BıocLIM (true-false, 1.25). Darker: overlapping areas; lighter: predicted only with MAXENT; intermediate tone: predicted only with BIOCLIM; Dots: training records. References for selected localities: RA: Río Apa, Co: Concepción, Y: Yapeyú, Z: Zelaya; Argentinean provinces: Mis: Misiones, Corr: Corrientes, ER: Entre Ríos, SF: Santa Fe, BA: Buenos Aires, For: Formosa, Ch: Chaco, Córd: Córdoba, SE: Santiago del Estero, Ju: Jujuy, Sal: Salta, Tu: Tucumán, Cat: Catamarca. (3) Model calibrated with MAXENT, showing suitability levels in four steps (from lighter to darker: 0.178-0.3; 0.3-0.5; 0.5-0.7; above 0.7). Dots: training records. References for selected localities: RA: Río Apa, A: Asunción, Re: Reconquista, VL: Valle de Lerma, SB: Sierra de Santa Bárbara, Co: Concepción, Y: Yapeyú, Z: Zelaya.

the software. The former is a heuristic estimation obtained by adding or subtracting (in each iteration of the training algorithm) the increase or decrease of regularized gain to the contribution of the corresponding variable (PHiLlips et al. 2011). The "permutation importance" results from values of each environmental variable in training presence data and background points being randomly permuted; the model is then reevaluated on the permuted data and the resulting drop in training AUC is normalized to percentages values. In addition, importance was also evaluated with the "jackknife test", which considers the training gain when the model is run with either one variable removed at a time or using that variable in isolation. The bc that decreases gain the most when omitted is deemed to have the most information not present in other variables; the bc with highest gain when run in isolation is considered to bear the most useful information by itself (PHILLIPs et al. 2011). The mentioned measures of relevance normally do not rank variables in the same order; therefore, the ranking shown in Table 2 reflects an overall scoring, following AcOsTA $\&$ Vergara (2013) and Acosta (2014). This overall score is calculated as: (a) percent contribution + (b) permutation importance - (c) jackknife test, without that variable + (d) jackknife test using the variable in isolation $(\mathrm{a}+\mathrm{b}-\mathrm{c}+\mathrm{d})$. As stated, the vari- ables ranking for relative overall contribution, obtained in a preliminary run with all 19 variables, was used as a criterion to retain relevant predictors of a correlated pair.

Aside from these general measurements, in a local dimension it is clear that the relevance of the variables is not the same in different portions of the range. To detect which predictor is the most limiting in each sector, a Most Limiting Factor (MLF) analysis was run using BIocLIM. MLF makes a grid-by-grid assessment of the variables, indicating for each positive cell (0-100 percentile) the variable for which the percentile score was the most extreme (lowest or highest; HiJMAns et al. 2005a).

\section{RESULTS}

\section{Records of Discocyrtus dilatatus}

The complete dataset comprised 85 unique localities, of which 49 are new records (Appendix 1, also displayed in Fig. $1)$; at the resolution employed, all points remained in independent grid-cells, i.e., all of them were effective records in the modeling procedure. Two literature records were not included in the dataset because they were not precise enough: "Nördl. Argentinien" [Northern Argentina] (Roewer 1913) and "Brazil, Santa Catarina" (Roewer 1929). The record for "Brazil: 
São Paulo, Alto da Serra" (Roewer 1929) needs verification (Acosta 1995) and was also disregarded. The original locality "La Zanja", Paraguay (SøRENSEn 1884) could not be found (ACOSTA 1995). Mello-Leitão (1939) mentioned the occurrence of $D$. dilatatus in "Uruguay", but this location was questioned by CAPocasale (1968) and Acosta (1995). There is a mistaken reference for "Bahía Blanca" (Roewer 1929), followed by Ringuelet (1959), but that record proved not to exist in Roewer's collections (Acosta 1995). Finally, Roewer (1929) cited the species for "Argentinien (Rio Salado)", which was attributed to the province of Santiago del Estero by Ringuelet (1959); however, labels of the original material (stored at the Muséum National d'Histoire Naturelle, Paris) read "Paraguay: Rio Salabro" (AcosTA 1995). We assume here that the latter is a misspelling of Río Salado, a tributary stream of the Paraguay River, $20 \mathrm{~km} \mathrm{~N}$ of Asunción (Appendix 1). The material collected by us substantially increased the number of known localities in the provinces of Corrientes, Santa Fe, Formosa, Córdoba and Salta, and recorded the species for the first time in the provinces of Misiones, Entre Ríos and Catamarca. Records obtained in the center of the province of Córdoba (Los Molinos, Despeñaderos 1, Despeñaderos 2 and Villa los Aromos) represent the westernmost localities for the species in the Mesopotamian s.s. sector of the range. Our observations confirmed that $D$. dilatatus is a frequent inhabitant of forested, humid and shady areas; proximity of watercourses does not seem as essential for this species, as it proved for some congeners (for instance $D$. testudineus; Acosta 2014). As reported by Acosta (1995), we caught the species preferentially under fallen trunks, and also in abandoned buildings, under piles of bricks or rubbles.

\section{Potential range}

SDMs built with MaXenT and Bioclim were broadly consistent, although the predictions of the latter were more permissive (Fig. 2). With MAXENT, the suitable area for $D$. dilatatus concentrated more tightly around most records in the core area, but left out some extreme points, for instance Yapeyú (on the coast of Uruguay River), Zelaya (province of Buenos Aires), Concepción, and Río Apa (Figs. 2, 3). In contrast, the wider prediction of BIoclim embraced the two former, Yapeyú and Zelaya, but with the adopted cutoff, Concepción and Río Apa (the western- and northernmost records, respectively) were also excluded from suitable grid-cells. Both methods predicted the disjunction between the core Mesopotamian area and the Yungas sector of the range. In the BIOcLIM model, a finger-like projection extends into the Bermejo River basin, entering the Chaco from the core area (Fig. 2); however, given that this projection did not build a full bridge, the disjunction remained. These results once again added support to the disjunct pattern: like other Mesopotamian harvestmen, the semi-arid Chaco appears to be an insurmountable region for $D$. dilatatus.

With MAXENT, two main sectors with higher suitability in the Mesopotamian portion were distinguished (Fig. 3). One extends along the Paraguay and Parana Rivers, approximately be- tween Asunción (A) and Reconquista (Re). The second highsuitability zone spreads over the plains of the province of Córdoba and southern Santa Fe. These areas are not isolated, but they are linked by a narrowed portion with lower probability (Fig. 3). In the Yungas sector, the highest levels of suitability concentrated in the Valle de Lerma, province of Salta (VL, Fig. 3) and the Sierra de Santa Bárbara - El Rey, province of Jujuy (SB). Localities placed on the borders of the Dry Chaco ecoregion (Monte Lindo Grande, 30 km of Formosa, San Francisco de Laishi and El Colorado, in province of Formosa; Presidente de la Plaza in province of Chaco), as well as the single record in province of Entre Ríos (Rosario del Tala), appeared highly marginal in the SDM and in the frequency curves (see below). As stated, some extreme points (Río Apa, Zelaya, Yapeyú, Concepción) were left outside the predicted area (Figs. 2, 3).

In all MAXENT models, the values of AUC were excellent. In the single model made with all 85 records, the AUC was 0.970; in the 30 replicates, training AUC averaged 0.9705 (range 0.96730.9760). For Bioclim, values of AUC revealed "good" accuracy (0.868-0.917; mean $=0.894,20$ replicates using training data $)$.

\section{Bioclimatic profile}

Table 1 summarizes the features describing the bioclimatic preferences of $D$. dilatatus: maximum, minimum, average and standard deviation for each variable, along with the type of distribution of cumulative frequency curves and the numbers of outliers. The bioclimatic profile indicates that $D$. dilatatus inhabits areas with temperate-warm climate, with mean annual temperature between $15.76^{\circ} \mathrm{C}$ and $24.97^{\circ} \mathrm{C}$, and annual rainfall widely ranging from 369 to $1757 \mathrm{~mm}$. Only six out of 19 variables showed outliers in the frequency distribution (Table 1): bc5-maximal temperature of warmest month, bc8-mean temperature of wettest quarter, bc14-precipitation of driest month, bc15-precipitation seasonality, bc17-precipitation of driest quarter and bc19-precipitation of coldest quarter.

Localities in Paraguay, in conjunction with records of the nearby province of Formosa, were the warmest and most thermally stable (Appendix 1): they were at the upper end in most cumulative frequency curves of absolute temperature variables (bc1, bc3, bc5, bc6, bc8, bc9, bc10, bc11), and showed the lowest values for variables that measure temperature variation (bc2, bc4, bc7). Rio Apa, in Paraguay, the northernmost record for the species, is accordingly the warmest locality, with the highest values for bc1, bc3, bc6, bc8, bc9, bc10, bc11 (Appendix 1) and the lowest seasonality (bc4). The most humid locality was Trinidad, in southern Paraguay, with the highest value for annual precipitation (bc12) and other four absolute precipitation variables (bc14, bc16, bc17, bc19). Moreover, Trinidad, together with Posadas and "Posadas-UC", also bore the upper outliers for bc14, bc17 and bc19; additionally, the latter locality had the lowest value of precipitation seasonality (bc15). These results revealed that this area (the boundary between Paraguay and province of Misiones) is the wettest portion of the range, with high rainfall during the entire year. As 
expected, median values for most temperature variables were concentrated in localities around the center of the core area, especially in provinces of Santa Fe and Córdoba (Silva: bc7; Lehmann: bc1, bc9 and bc11; Estancia Yucat: bc2; Monte leña: bc3; Marcos Juárez: bc5; Brinkman: bc6; Villa del Tránsito: bc8) (Appendix 1). The coldest climate in the species' profile was represented by NWA localities (bc1, bc5, bc6, bc8 and bc10), Bell Ville in Córdoba (bc9) and Zelaya in Buenos Aires (bc3, bc11) (Table 1). The prevalence of a cooler climate in NWA localities can be attributed to their altitude, the highest in the entire range of the species. This region is also, in general, characterized by strong thermal fluctuations: NWA records were at the upper ends of bc2-mean monthly temperature range and bc3-isothermality. In general, NWA localities have strong rainfall seasonality, with precipitation mostly concentrated in the summer. El Corte-El Paraíso showed the highest values for bc 13 (precipitation of wettest month) and bc18 (precipitation of warmest quarter), while $2 \mathrm{~km}$ from Virrey Toledo, $5 \mathrm{~km}$ from Virrey Toledo, Rosario de Lerma and Quebrada de Tilián had the lowest bc14 values (precipitation of driest month); Quebrada de Tilián had also the strongest precipitation seasonality (bc15), as well as the lowest values for bc17 (precipitation of driest quarter) and bc19 (precipitation of coldest quarter). The most "severe" climate for the species seemed to be in Concepción (Catamarca), with the highest temperature seasonality (bc4) and annual temperature range (bc7), and also the lowest values for four absolute precipitation variables (bc12, bc13, bc16, bc18). It is worth noting that no locality of the core sector bordering the Dry Chaco (provinces of Chaco and Formosa) appeared at or near the driest end on the corresponding frequency curves, thus suggesting that precipitation features in this sector are not as critical as previously thought. In contrast, a single temperature variable (bc5) was extreme for San Francisco de Laishi (Formosa) and around the highest end in several neighboring sites; as shown below, it is likely that this variable has a limiting role in this portion of the range.

\section{Relevance of variables}

The final ranking of the overall relevance of the variables tested, as calculated in MAXENT, is displayed in Table 2. On top ranked bc4-temperature seasonality, which at the same time had the highest "permutation importance" and the second highest "percent contribution". This variable is one measure of thermal regularity during the year. In contrast, other variables indicating climate regularity (bc7-temperature annual range or bc15precipitation seasonality) were only moderately relevant (Table 2). When percent contribution alone is taken into account, bc18precipitation of warmest quarter ranked the highest, and second in the overall rating (Table 2); this revealed the importance of rainfall during summer, which is the most humid season in most of the area. This variable (bc18) was also the climatic predictor that decreased the gain the most, when omitted in the jackknife test without a variable (Table 2). As for the second jackknife test ("with only"), the variable with the highest gain when used in isolation was bc9-mean temperature of driest quarter, which ranked the fourth in the overall score. It should be noted that, of the five top ranked variables, four corresponded to temperature variables, suggesting that these are in general more influential in MAXENT models. Only the sixth place is again occupied by a precipitation variable, bc15-precipitation seasonality, although with moderate overall importance (Table 2). This seems to be in agreement with some informal tests we carried out with Brocum (not shown in this paper), in which models built using the temperature variables alone were more similar to the default models (11 variables) than those calibrated with precipitation variables. A striking result of the latter was the disappearance of the Chaco disjunction when only precipitation variables were employed.

Results of the MLF analysis supported the importance of temperature variables, which were limiting in most of the Mesopotamian sector, covering a large area across the provinces of Formosa, Chaco, Santa Fe, Entre Ríos and Córdoba, as well as the borders of the Yungas sector (Fig. 4). The local importance of bc5-maximal temperature of warmest month seems revealing in this analysis, since it was arranged in the boundaries between the species' range and the Dry Chaco. As seen, no precipitation variable posed a limit for the species to enter

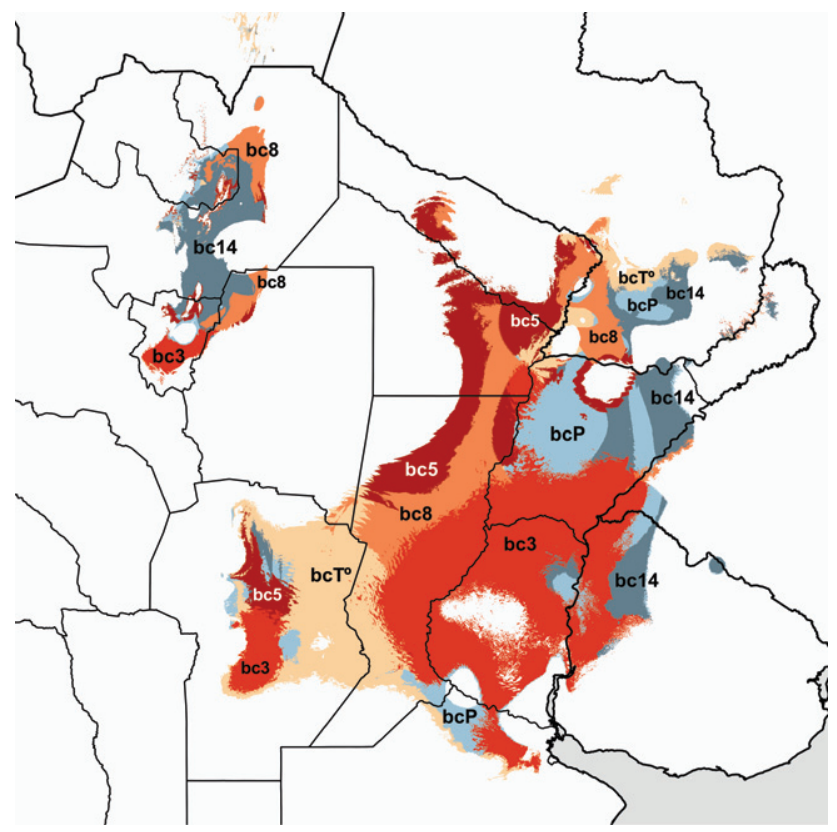

Figure 4. Results of the Most Limiting Factor analysis (BIOCLIM) of Discocyrtus dilatatus, performed with the 11 selected bc variables. For clarity, map displays only the four more relevant variables (bc3isothermality, $\mathrm{bc} 5$-maximal $\mathrm{T}^{\circ}$ of warmest month, $\mathrm{bc} 8$-mean $\mathrm{T}^{\circ}$ of wettest quarter, and bc14-precipitation of driest month). Other less influential temperature and precipitation variables are displayed together as $\mathrm{bcT}^{\circ}$ and bcP, respectively. 
the Chaco. In contrast, precipitation variables resulted more critical than temperature variables in most of the Yungas, in this case because of the influence of the reduction of precipitations in the driest month (bc14). It is noteworthy that the same variable (bc14) was also recognized as limiting at the eastern borders of the core range, but there the constraint was a function of its high values (the region turning "too rainy" with respect to this variable towards the East).

\section{DISCUSSION}

Despite their large areas of agreement, the models yielded by MAXENT and Bioclim for $D$. dilatatus have some noteworthy differences (Fig. 2). Like for other modeled harvestmen (AcosTA \& Guerrero 2011, Acosta \& Vergara 2013, Acosta 2014), the Biocuim results for $D$. dilatatus were clearly more permissive: this method predicted large areas in the Mesopotamia (especially in provinces of Entre Ríos and Corrientes) and in western Uruguay as suitable, while MAXENT rated them as unsuitable (Fig. 2); thereby, the Biocum model embraced one marginal locality (Yapeyú) that was left outside in the more conservative MaXent model. Bioclim also exceeded Maxent in some portions advancing into the Chaco, especially the "finger-like" projection around the Bermejo River basin (Fig. 2). In contrast with the results of BIOCLIM, MAXENT added some small extra regions in Paraguay, although predictions of both methods ended around $-24^{\circ} \mathrm{S}$ (San Pedro), thus leaving the northernmost record at Río Apa far outside. The predictions of both models strongly agreed at the Yungas, with Bioclim projecting a little more into the eastern plains, and MAXENT more continuously into the North (Fig. 2). It is well known that no single modeling method has the "absolute truth" (ELITH et al. 2006, WARD 2007, MARMION et al. 2009), so that looking for agreement areas is helpful to find where the predictions are most likely accurate. One remarkable discordance between models was observed in the north of province of Santa Fe (Fig. 2), near the boundaries between two ecoregions, the Humid Chaco and the Espinal (Fig. 1). With MAXENT, prediction in this sector was assigned the lowest suitability, and formed a somewhat narrow "corridor" between the two large high-suitability portions of the core range (Fig. 3); such narrowing was not insinuated by Bioclim. At the same time, records in this sector seem to leave a gap, which may explain the weak local prediction of MAXENT. The lack of records there might not be just an artifact, but reflect edaphic and physiognomic causes: the referred region corresponds to a large depressed grassland area in the southern portion of the Humid Chaco, the "Sub-meridional shallow plains" (GINZburG \& ADÁmoli 2006), characterized by poor drainage and argillaceous soils that contribute to it becoming a swamp for several months in the rainy season (thereby appearing not really suitable for $D$. dilatatus).

As already supported by SDMs calibrated for D. prospicuus and $G$. orensis, the other Mesopotamian harvestmen with a dis- junct range (Acosta \& Guerrero 2011, Acosta \& Vergara 2013), the distributional gap on the Chaco was also predicted by the bioclimatic models of $D$. dilatatus. Thus, the disjunction does not seem to be a mere sampling artifact. However, no matter how sophisticated the modeling procedure is, actual records will always have the last word to test the pattern (Eurth et al. 2006, Guisan \& Thuiller 2005). As reported by Acosta \& Vergara (2013), a collecting effort was carried out on a $500 \mathrm{~km}$ transect across the Dry Chaco, most sampling sites placed on or near National Highway 81 . From East to West, localities included El Colorado $\left(-59.358182^{\circ} \mathrm{W}\right)$, Villa Rio Bermejito $\left(-60.267152^{\circ} \mathrm{W}\right)$; meander near Estanislao del Campo $\left(-60.086645^{\circ} \mathrm{W}\right)$; near Las Lomitas ($\left.60.695801^{\circ} \mathrm{W}\right)$; Highway 39, bridge over Teuquito river ($\left.61.934790^{\circ} \mathrm{W}\right) ; 50 \mathrm{~km} \mathrm{~S}$ Ingeriero Juárez $\left(-61.941029^{\circ} \mathrm{W}\right)$; and Pichanal $\left(-64.233733^{\circ} \mathrm{W}\right)$. Up to Las Lomitas, this transect was also well-suited to survey along the "finger-like projection" into the Chaco, as predicted by Bioclim (Fig. 2). Except for El Colorado, all sites were too xeric and resulted completely negative for any Mesopotamian harvestman, D. dilatatus included (AcostA $\&$ Vergara 2013). This empiric evidence for the disjunction seems thus better depicted by the abrupt end of distribution predicted by MAXENT models in that area, than the more permissive results yielded by Biocum (Figs. 2, 3). The strength of the pattern was revealed by a simple "counterfactual" exercise (not shown), using both BIOCLIM and MAXENT: with the same "trans-Chacoan" localities included in the data set, as if they were positive records, the models depicted suitable areas invading the Chaco, but always keeping the disjunction.

Like for other harvestmen previously modeled, different lines of evidence indicate that temperature variables are the main constraints in the distribution of $D$. dilatatus, more than precipitation variables. The most relevant predictor (in MAXENT model) was bc4-temperature seasonality (Table 2). This variable, clearly expressing the thermal stability throughout the year, also ranked on top for $D$. testudineus and G. orensis (Acosta \& Vergara 2013, Acosta 2014), suggesting that its relevance might be generalized to other Mesopotamian harvestmen. In the case of $D$. prospicuus, whose range can be considered marginal in the area, bc4 ranked second in relevance (Acosta \& Guerrero 2011), thus still revealing a strong influence in the final results. The second most relevant variable for $D$. dilatatus was bc18-precipitation of warmest quarter, the only precipitation predictor that ranked among the top-five (Table 2). There was little agreement regarding the relevance of bc18 in the distribution models of other Mesopotamian harvestmen: in $D$. testudineus and D. prospicuus its importance was quite moderate (it was not used to model in G. orensis); instead, bc14precipitation of driest month, the least important for $D$. dilatatus, ranked high and proved to be much more influential for D. testudineus and G. orensis (Acosta \& GUerrero 2011, Acosta \& Vergara 2013, Acosta 2014). Interestingly, among the mentioned species, $D$. dilatatus seems to be the least dependent on humidity (AcosTA 2014), which most likely means that lower 
precipitation rates are not as critical for it as for the rest. Although their ranges largely overlap and they are frequently collected together, there is clear evidence of some differences in the bioclimatic niches of these Mesopotamian harvestmen (Acosta 2014).

The influence of temperature variables is also well reflected in the results of the Most Limiting Factor analysis, in which they monopolize the largest portion of the core range (Fig. 4). In a regional scale, bc5-maximal temperature of warmest month was recognized as the most critical in the boundaries with the inhospitable sub-xeric Chaco. Although not very relevant in the overall analysis (Table 2), this variable might explain the sudden end of the distribution observed in that sector: as already pointed out by AcosTA (2014), Mesopotamian harvestmen appear to meet a rigid climatic constraint where bc5 reaches $34.40^{\circ} \mathrm{C}\left(D\right.$. dilatatus, D. testudineus) or $34.60^{\circ} \mathrm{C}(G$. orensis). Rainfall represents no limitation in the Chaco, as suggested by the continuous range (no disjunction) obtained in informal Biocurm runs using precipitation variables alone. High maximal temperatures, instead of low precipitation, are clearly the factor preventing these harvestmen from entering the Dry Chaco. In fact, most of this ecoregion is embraced by the $47^{\circ} \mathrm{C}$ isotherm of maximal temperatures (absolute record of $48.9^{\circ} \mathrm{C}$ in eastern province of Salta), thereby denoted as the "South American pole of heat" (Prado 1993, Acosta \& Vergara 2013). It can be assumed that other kinds of variables, like evapotranspiration (not available in this study), might probably be better suited to describe this climatic restriction. Despite the incipient current knowledge, SANTOS (2007) suggested that harvestmens' inability to control water loss, based on several morphological and physiological features, constitutes a major weakness of most species. It looks that ecophysiological studies are needed to find out whether the supposedly negative effects of bc5 on Mesopotamian harvestmen are direct or indirect (e.g., by raising evapotranspiration rates). In any case, the results of our bioclimatic modeling approach represent a valid shortcut to a preliminary understanding of the bioclimatic preferences of the species, otherwise completely unknown.

\section{ACKNOWLEDGMENTS}

We are indebted to Gonzalo Rubio, Luis Vaschetto, Raúl González-Ittig, Mónica García, Carina Argañaraz, Lucas Paoloni, Pedro Vergara, Maria Oficialdegui and Patricia Iglesias for their valuable help during the collecting trips. Cristina Scioscia (MACN) and Marcela Peralta (IML) enabled LEA to study additional specimens in the mentioned collections. JV is currently a postdoctoral fellow and LEA a researcher of the Consejo Nacional de Investigaciones Científicas y Técnicas (CONICET), Argentina. This research received financial support (given to LEA) from CONICET (PIP Res. 918/10), Agencia Nacional de Promoción Científica y Tecnológica (FONCYT - PICT 1296), and SECYT - Universidad Nacional de Córdoba.

\section{LITERATURE CITED}

Acosta LE (1995) Nuevos hallazgos de Discocyrtus dilatatus en Argentina, con notas de taxonomía, sinonimia y distribución (Opiliones, Gonyleptidae, Pachylinae). Revue Arachnologique 10(12): 207-217.

Acosta LE (2002) Patrones zoogeográficos de los opiliones argentinos (Arachnida: Opiliones). Revista Ibérica de Aracnología 6: 69-84.

Acosta LE (2008) Distribution modeling of Geraeocormobius sylvarum (Opiliones, Gonyleptidae) based on bioclimatic variables. The Jounal of Arachnology 36(3): 574-582. doi: 10.1636/T07-36.1

Acosta LE (2014) Bioclimatic profile and potential distribution of the Mesopotamian harvestman Discocyrtus testudineus (Holmberg, 1876) (Opiliones, Gonyleptidae). Zootaxa 3821(3): 301-320. doi: 10.11646/zootaxa.3821.3.1

Acosta LE, Guerrero EL (2011) Geographical distribution of Discocyrtus prospicuus (Arachnida: Opiliones: Gonyleptidae): Is there a pattern? Zootaxa 3043: 1-24.

Acosta LE, Vergara J (2013) New records and distribution modeling of Gryne orensis (Sørensen) (Opiliones, Cosmetidae) support the Mesopotamian-yungas disjunction in subtropical Argentina. Zootaxa 3736(2): 143-158. doi: 10.11646/zootaxa. 3736.2.3

CAPOCASAle R (1968) Nuevos aportes para el conocimiento de la distribución geográfica de los opiliones del Uruguay. Neotrópica 14(44): 65-71.

Di Rienzo JA, Casanoves F, Balzarini MG, Gonzalez L, Tablada M, Robledo CW (2013) InfoStat versión 2013. Córdoba, Grupo InfoStat, FCA, Universidad Nacional de Córdoba. Available online at: http://www.infostat.com.ar [Accessed: 14/08/2013]

Elith J, Graham CH, Anderson RP, Dudik M, Ferrier S, Guisan A, Hijmans RJ, Huettmann F, Leathwick JR, Lehmann A, Li J, Lohmann LG, Loiselle BA, Manion G, Moritz C, Nakamura M, Nakazawa Y, Overton JM, Peterson AT, Phillips SJ, Richardson K, ScachettiPereira R, Schapire Re, Soberon J, Williams S, Wisz MS, ZIMMERMANN NE (2006) Novel methods improve prediction of species' distributions from occurrence data. Ecography 29(2): 129-151. doi: 10.1111/j.2006.0906-7590.04596.x

Elith J, Leathwick JR (2009) Species Distribution Models: Ecological explanation and prediction across space and time. Annual Review of Ecology, Evolution and Systematics 40: 677-697. doi: 10.1146/annurev.ecolsys.110308.120159

Ginzburg R, AdÁmoli J (2006) Situación ambiental en el Chaco Húmedo, p. 103-113. In: Brown A, Martínez-Ortiz U, Acerbi M, CORCUERA J (Eds.) La situación ambiental argentina 2005. Buenos Aires, Fundación Vida Silvestre Argentina, 587p.

Guisan A, Thuiller W (2005) Predicting species distribution: offering more than simple habitat models. Ecology Letters 8(9): 993-1009. doi: 10.1111/j.1461-0248.2005.00792.x

Guisan A, Zimmermann NE (2000) Predictive habitat distribution 
models in ecology. Ecological Modelling 135(2-3): 147-186. doi: 10.1016/S0304-3800(00)00354-9

Hijmans RJ, Cameron SE, Parra JL, Jones PG, Jarvis A (2005a) Very high resolution interpolated climate surfaces for global land areas. International Journal of Climatology 25(15): 19651978. doi: 10.1002/joc.1276

Hijmans RJ, Guarino L, Jarvis A, O’Brien R, Mathur P, Bussink C, Cruz M, Barrantes I, Rojas E (2005b) DiVA-GIS. Version 5.4.0.1. Available online at: http://www.diva-gis.org [Accessed: 14/08/2013]

Kozak KH, Graham CH, Wiens JJ (2008) Integrating GIS-based environmental data into evolutionary biology. Trends in Ecology and Evolution 23(3): 141-148. doi: 10.1016/j.tree.2008.02.001

Liu C, Berry PM, Dawson TP, Pearson RG (2005) Selecting thresholds of occurrence in the prediction of species distributions. Ecography 28(3): 385-393. doi: 10.1111/ j.0906-7590.2005.03957.x

Luoto M, Pöyry J, Heikrinen RK, SAarinen K (2005) Uncertainty of bioclimate envelope models based on the geographical distribution of species. Global Ecology and Biogeography 14(6): 575-584. doi: 10.1111/j.1466-822X.2005.00186.x

Marmion M, Parviainen M, Luoto M, Heikkinen RK, Thuiller W (2009) Evaluation of consensus methods in predictive species distribution modelling. Diversity and Distributions 15(1): 59-69. doi: 10.1111/j.1472-4642.2008.00491.x

Mello-Leitão C (1939) Les arachnides et la zoogéographie de l'Argentine. Physis 17(49): 601-630.

Müller A (1918) Einige neue Gonyleptiden. Zoologischer Anzeiger 49(3-4): 89-94.

Nores M (1992) Bird speciation in subtropical South America in relation to forest expansion and retraction. The Auk 109(2): 346-357.

Oison DM, Dinerstein E, Wikramanayake ED, Burgess ND, Powell GVN, Underwood EC, D'Amico JA, Itoua I, Strand HE, Morrison JC, Loucks CJ, Allnutt TF, Ricketts TH, Kura Y, Lamoreux JF, WetTengel WW, Hedao P, Kassem KR (2001) Terrestrial ecoregions of the world: A new map of life on Earth. BioScience 51(11): 933938. doi: 10.1641/0006-3568(2001)051[0933:TEOTWA]2.0.C

Pearson RG (2010) Species' distribution modeling for conservation educators and practitioners. Lessons in Conservation (3): 54-89. Available online at: http://www.amnh.org/our-research/center-forbiodiversity-conservation/publications/lessons-in-conservation/ lessons-in-conservation-issue-iii [Accessed: 20/03/2013]

PhILLIPS SJ, ANDERSOn RP, SCHAPIRE RE (2006) Maximum entropy modeling of species geographic distributions. Ecological Modeling 190(3-4): 231-259. doi: 10.1016/j.ecolmodel.2005.03.026
Phillips SJ, Dudik M, SchapiRe R (2011) Maximum Entropy Modeling of Species Geographic Distributions [MAXENT]. Version 3.3.3k. Available online at: http://www.cs.princeton.edu/ schapire/ maxent [Accessed: 20/05/2013]

Prado DE (1993) What is the Gran Chaco vegetation in South America? I. A review. Contribution to the study of flora and vegetation of the Chaco. V. Candollea 48(1): 145-172.

Raxworthy CJ, Martinez-Meyer E, Horning N, Nussbaum RA, Schneider Ge, Ortega-Huerta MA, Peterson AT (2003) Predicting distributions of known and unknown reptile species in Madagascar. Nature 426: 837-841. doi: 10.1038/nature02205

Ringuelet RA (1959) Los arácnidos argentinos del Orden Opiliones. Revista del Museo Argentino de Ciencias Naturales 5(2): 127-439.

Rissler LJ, Apodaca JJ (2007) Adding more ecology into species delimitation: Ecological niche models and phylogeography help define cryptic species in the black salamander (Aneides flavipunctatus) Systematic Biology 56(6): 924-942. doi: 10.1080/10635150701703063

Roewer CF (1913) Die Familie der Gonyleptiden der OpilionesLaniatores. Archiv für Naturgeschichte 79A(4): 1-256.

RoEWER CF (1929) Weitere Weberknechte III. III Ergänzung der Weberknechte der Erde, 1923. Abhandlungen herausgegeben vom Naturwissenschaftlichen Verein zu Bremen 27(2): 179-284.

ROEWER CF (1938) Opiliones aus dem Naturhistorischen Reichsmuseum in Stockholm. Arkiv för Zoologi 30B(10): 1-10.

Rubio GD, Acosta LE (2011) Geographical distribution of the space-weaving spider, Chibchea salta, from northwestern Argentina: New records and bioclimatic modeling. Journal of Insect Science 11(1): 54. doi: 10.1673/031.011.5401

SAntos FH (2007) Ecophysiology, p. 473-488. In: PInTo-DA-Rocha R, Machado G, Giribet G (Eds.) Harvestmen: The Biology of Opiliones. Cambridge, Harvard University Press, 597p.

SOARES HEM, SOARES BAM (1985) Contribution á l'étude des opilions (Opiliones: Cosmetidae, Phalangodidae, Gonyleptidae) du Paraguay. Revue Suisse de Zoologie 92(1): 3-18.

Sørensen W (1884) Opiliones Laniatores (Gonyleptides W.S. olim) Musei Hauniensis. Naturhistorisk Tidsskrift, Ser. 3 14: 555-646.

SøRENSEN W (1895) Viaggio del dottor Alfredo Borelli nella Repubblica Argentina e nel Paraguay. XVII. Opiliones Laniatores. Bolletino dei Musei di Zoologia ed Anatomia Comparata della R. Università di Torino 10(210): 1-6.

WARD DF (2007) Modeling the potential geographic distribution of invasive ant species in New Zealand. Biological Invasions 9(6): 723-735. doi: 10.1007/s10530-006-9072-y

Submitted: 27 May 2015

Received in revised form: 3 August 2015

Accepted: 29 August 2015

Editorial responsibility: Ricardo Pinto da Rocha

ZOOLOGIA 32 (6): 445-456, December 2015 


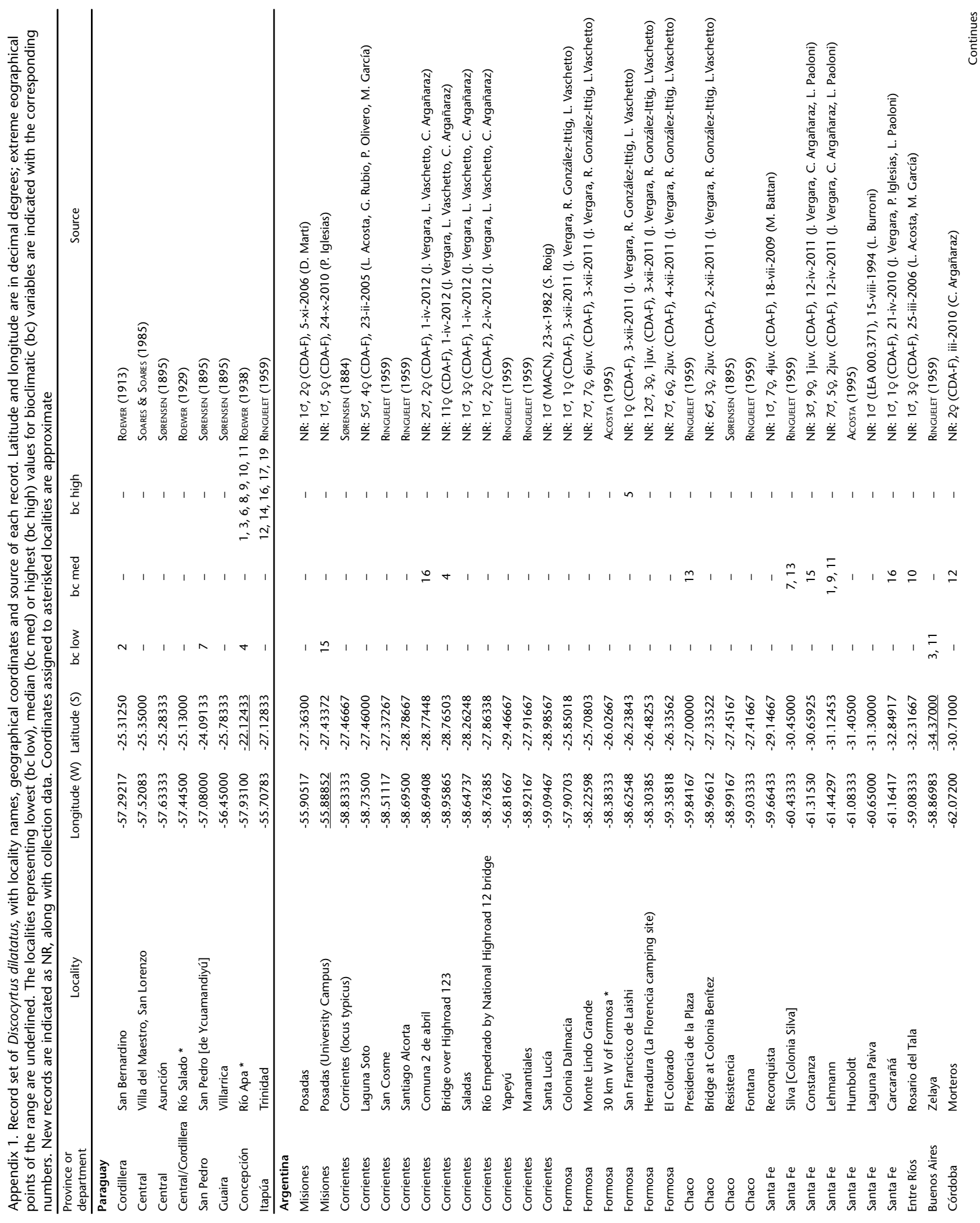




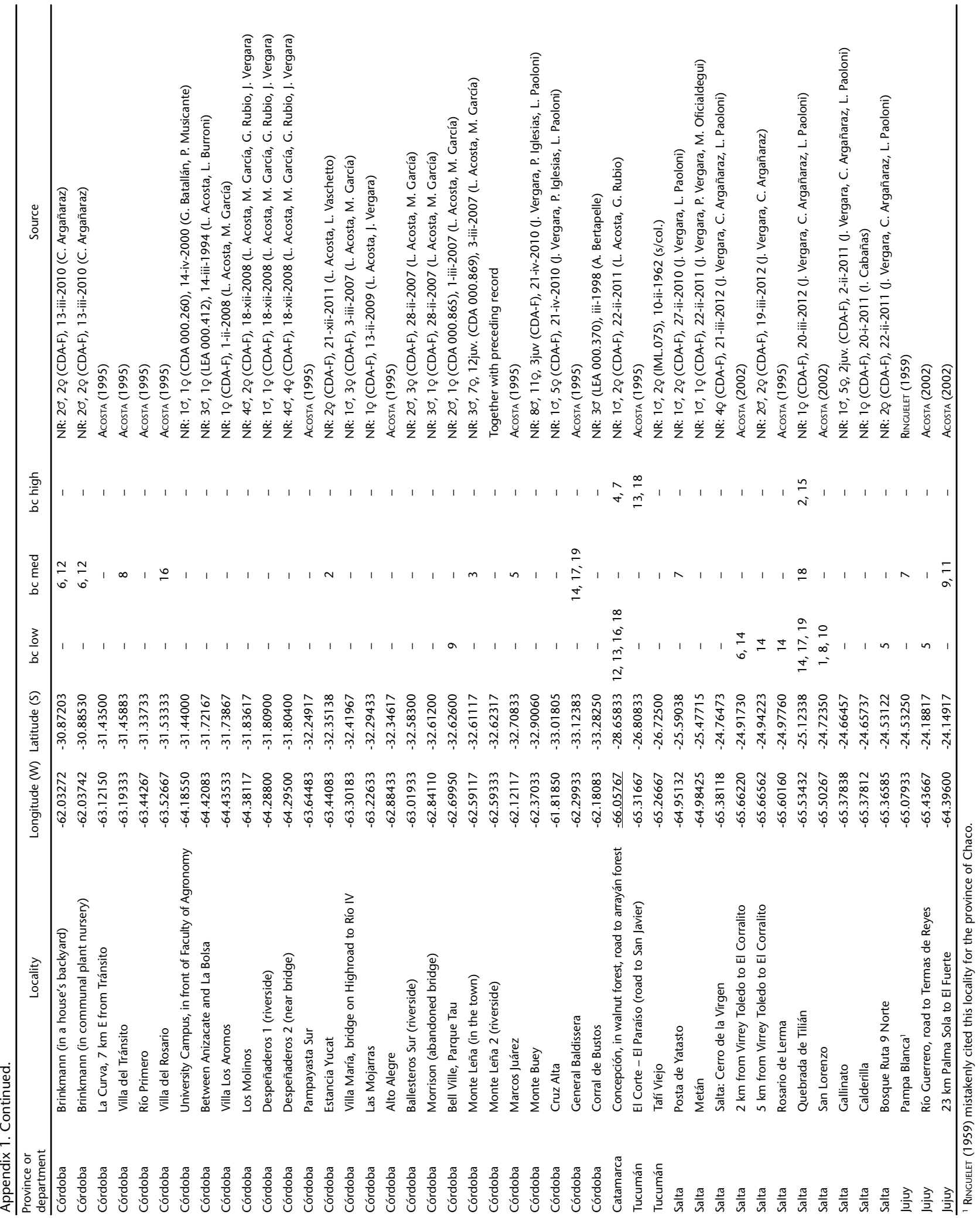

